\title{
Effect of exogenous progesterone on superovulatory response in heifers inseminated with fresh or frozen semen
}

\author{
D. Goulding, D. H. Williams, J. F. Roche and M. P. Boland* \\ National Agricultural and Veterinary Biotechnology Programme, University College Dublin, \\ Belfield, Ireland
}

\begin{abstract}
Superovulation in cattle normally involves the administration of gonadotrophins at specific times of the oestrous cycle, followed by the induction of luteolysis and insemination with high quality semen. The first aim of this experiment was to examine the effect of supplementary progesterone when used in conjunction with porcine $\mathrm{FSH}(\mathrm{pFSH})$ to induce superovulation in heifers. The methods compared were $\mathrm{PGF}_{2 \alpha}$ given at mid-cycle or a progesterone-releasing intravaginal device (PRID) inserted at different phases of the cycle. The second aim was to determine whether site of insemination or use of fresh or frozen semen affected embryo production. A factorial design was used involving 185 beef heifers. The main factors were (i) synchronization methods $\left(\mathrm{PGF}_{2 \alpha}\right.$ or PRID); (ii) semen type (fresh or frozen); (iii) insemination regimens (involving two inseminations and variations in the sites) and number of straws used (one or two) at the second insemination. Eight injections of pFSH were given twice a day for 4 days starting either on days 9,10 or 11 of the oestrous cycle or on the fourth day after insertion of a PRID. Heifers were checked for oestrus, inseminated twice and embryos were recovered on day 7 of the superovulated cycle. There was no difference between heifers given either PRID or PGF P $_{2 \alpha}$ in the oestrous response ( $93 \%$ versus $96 \%$ ), number of ovulations ( $15.9 \pm 1.11$ versus $13.4 \pm 1.06$ ), large follicles $(2.5 \pm 0.24$ versus $2.3 \pm 0.23$ ) or embryos recovered $(9.1 \pm 0.77$ versus $9.1 \pm 0.74)$. The number of embryos that could be frozen was lower $(P=0.05)$ in heifers given PRID. The stage of the cycle at which the PRID was inserted affected the number of ovulations, large follicles and embryos recovered $(P<0.04)$. The use of fresh or frozen semen had no effect on the number of embryos recovered, but the use of frozen semen resulted in fewer grade 1 and 2 embryos and more grade 4 and 5 embryos in PRID-treated heifers. The number of straws did not affect the number or quality of embryos recovered. In conclusion, the use of a PRID, inserted at different stages of the cycle, in conjunction with PGF $_{2 \alpha}$ and pFSH resulted in fewer freezable embryos recovered compared with the use of $\mathrm{PGF}_{2 \alpha}$ and pFSH given at mid-cycle. The use of frozen semen did not affect the number or quality of embryos recovered following the use of $\mathrm{PGF}_{2 \alpha}$ and $\mathrm{pFSH}$ at mid-cycle, but it did decrease the number of grade 1 and 2 embryos recovered following the use of PRID and PFSH; the number (two versus three) of straws used did not affect the yield or quality of embryos recovered.
\end{abstract}

\section{Introduction}

The current gonadotrophin of choice for effective superovulation and high embryo recovery rates in cattle is porcine FSH (pFSH) (Boland et al., 1991) because it results in significantly more embryos recovered compared with the use of equine chorionic gonadotrophin. The stage of the oestrous cycle at which the gonadotrophin treatment is initiated affects the ovulatory response, owing presumably to the sequential periods of selection of a dominant follicle and

*Correspondence and reprint requests.

Received 4 June 1993. exertion of the dominance effects throughout the oestrous cycle (Ireland and Roche, 1987; Savio et al., 1988; Sirois and Fortune, 1988). The current most common protocol to superovulate cattle is injections of $\mathrm{pFSH}$ twice a day for 4 days between days 9 and 12 of the cycle in association with the use of a luteolytic dose of $\mathrm{PGF}_{2 \alpha}$ on the third day of treatment (Boland et al., 1991). This method, however, requires selection of animals for treatment based on a specific day of the oestrous cycle. In contrast, ewes can be effectively superovulated using gonadotrophins given towards the end of a 12-14 day progestagen treatment, initiated without reference to the stage of the cycle (Boland et al., 1983). However, there are relatively few comparable data available 
on superovulation in conjunction with progestagen treatment in cattle (Holtz et al., 1979; Almeida, 1987). If multiple injections of $\mathrm{FSH}$ at, or near the end of, a progesteronetreatment period give results similar to the use of FSH and $\mathrm{PGF}_{2 \alpha}$ at mid-cycle, the use of progesterone will obviate the need to detect oestrus before initiation of superovulation of donors. Accordingly, the first aim of this experiment was to compare embryo production rates in heifers given $\mathrm{pFSH}$ either at a known stage of the cycle with $\mathrm{PGF}_{2 \alpha}$ or towards the end of a 7 day progesterone treatment, and $\mathrm{PGF}_{2 \alpha}$ where treatment was initiated at three different stages of the cycle.

The use of progesterone to synchronize oestrus in ewes results in a requirement for high numbers of spermatozoa to achieve normal fertility (Boland et al, 1983). In addition, freezing of spermatozoa increases the number of dead spermatozoa, decreases motility after thawing and reduces their fertilizing capacity. In multiple ovulating animals, such as sows, there is a relationship between the establishment of a viable proportion of highly fertile spermatozoa at the utero-tubal junction and isthmus of the oviduct and fertilization rate (Hunter, 1988). Failure of a proportion of eggs to be fertilized in superovulated cattle may be associated with an initial depletion of the functional sperm reservoirs and a subsequent shortage of viable sperm cells in the proximal portion of the oviduct during the protracted period of ovulation (Hunter, 1988). A means of overcoming the diminished fertility might be to combine the routine technique of intrauterine insemination with simultaneous deposition of spermatozoa in the cervix. A prolonged release and migration of spermatozoa from the cervical mucus could then compensate for a depleted reservoir in the oviduct. Accordingly, the second aim of this experiment was to determine the effect of number of straws used, the use of fresh or frozen-thawed semen and varying the site of semen deposition (cervical or uterine) on embryo production in superovulated heifers.

\section{Materials and Methods}

\section{Animals and treatments}

A group of 185 Simmental and Charolais cross-heifers aged 18-24 months were maintained in a slatted unit with access to water ad libitum. They were fed a complete diet of silage, brewers grains and corn gluten that was calculated to give a minimum daily liveweight gain of $0.7 \mathrm{~kg}$ day $^{-1}$. The reproductive tracts of all heifers were palpated via the rectum before the study to establish normality and to allow selection of non-pregnant heifers. Heifers were given $15 \mathrm{mg}$ of a $\mathrm{PGF}_{2 \alpha}$ analogue (luprostiol: Prosolvin; Intervet Ltd, Boxmeer) to synchronize oestrus before superovulation. Oestrous detection was carried out for 20 min four times a day at 07:00, $12: 00,17: 00$ and $21: 00 \mathrm{~h}$ by visual observation (day of oestrus $=$ day 0 ).

A factorial design was used and the main factors were: (i) synchronization methods that were either an injection of $\mathrm{PGF}_{2 \alpha}$ analogue alone (cloprostenol, Estrumate, Coopers, Bray, Co. Wicklow) at mid-cycle (days $11-13 ; n=91$ ) to induce luteolysis or the insertion of a progesterone-releasing intravaginal device (PRID; Sanofi Animal Health, Watford) without

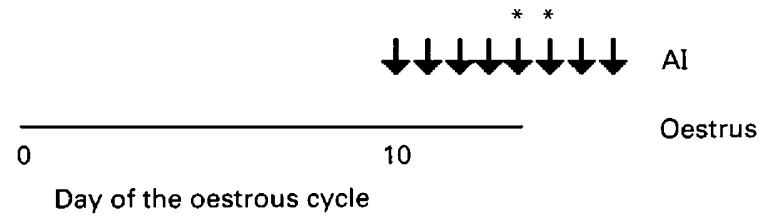

PRID treatments ${ }^{\dagger}$

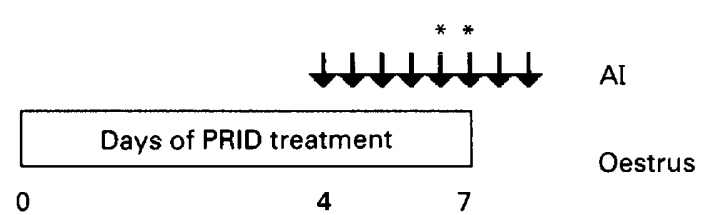

Fig. 1. Superovulation schedule used for heifers. PGF ${ }_{2 \alpha}$ was used alone, or in conjunction with a progesterone-releasing device (PRID), to induce luteolysis following injections of porcine FSH given twice a day for 4 days. ${ }^{+}$The PRID was inserted on days $1-3,6-8$ or $16-18$ of the oestrous cycle. AI: artificial insemination. $\downarrow$ each injection of FSH. * Injections of prostaglandin analogue.

Table 1. Site of insemination and number of straws used for insemination of heifers

\begin{tabular}{lccc}
\hline Insemination & First & & Second \\
\hline $\begin{array}{l}\text { Number of straws } \\
\text { Placement of semen }\end{array}$ & 1 & 1 & 1 \\
& Uterus & Cervix & - \\
& Uterus & Uterus & - \\
& Uterus & Uterus & Cervix \\
& Uterus & Uterus & Uterus \\
\hline
\end{tabular}

the oestradiol benzoate capsule for 7 days and PGF $_{2 a}$ given on the sixth day of PRID treatment, with PRIDs being inserted during the early luteal (days $1-3, n=35$ ), mid-luteal (days 6-8; $n=25$ ) or late luteal (days $16-18 ; n=24$ ) stages of the cycle, respectively (Fig. 1); (ii) use of fresh or frozen-thawed semen; (iii) site of semen deposition (intrauterine or cervical placement) and number of semen straws (two or three) (Table 1).

The pFSH (Folltropin: Vetrepharm, London, Ontario) was given twice a day for 4 days using doses of $4.5,3.5,2.5$ and $1.5 \mathrm{mg}$ per injection day ${ }^{-1}$, respectively, (total dose of $275 \mathrm{mg}$ NIH-FSH-P1 per heifer). The pFSH injections were started on days 9-11 of the oestrous cycle in the heifers given $\mathrm{PGF}_{2 \alpha}$ and on the fourth day of progesterone treatment ( $60 \mathrm{~h}$ before PRID withdrawal) in the PRID-treated heifers. Luteolysis was induced in all heifers by injections of cloprostenol at the fifth $(500 \mu \mathrm{g})$ and sixth $(250 \mu \mathrm{g}) \mathrm{pFSH}$ injections; the PRID was removed at the time of the second $\mathrm{PGF}_{2 \alpha}$ injection. Observations for standing oestrus began $24 \mathrm{~h}$ after the second $\mathrm{PGF}_{2 \alpha}$ injection. The first insemination was carried out by the same technician $8-12 \mathrm{~h}$ after the onset of oestrus and the second approximately $12 \mathrm{~h}$ later.

Semen from two bulls of known high fertility was used throughout the experiment. A single ejaculate of comparable quality was obtained each morning, and the ejaculate was split 
Table 2. Superovulatory response (injections of porcine FSH twice a day for 4 days) and embryo production rate (mean \pm SEM) in heifers given $\mathrm{PGF}_{2 \alpha}$ at mid-cycle (days $11-13$ ), or a 7-day PRID treatment and PGF $_{2 \alpha}$ before PRID removal. PRIDs were inserted at the early, mid- or late luteal phase of the oestrous cycle

\begin{tabular}{lcc}
\hline & \multicolumn{2}{c}{ Method of synchronization } \\
Number of & PGF $_{2 \alpha}$ & PRID plus PGF $_{2 \alpha}$ \\
\hline Heifers treated & 95 & 90 \\
Heifers in oestrus & 91 & 84 \\
Ovulations & $13.4 \pm 1.06$ & $15.9 \pm 1.11$ \\
Large follicles ( > 10 mm) & $2.3 \pm 0.23$ & $2.5 \pm 0.24$ \\
Embryos recovered & $9.1 \pm 0.74$ & $9.1 \pm 0.77$ \\
Freezable embryos (grade 1 and 2) & $4.4 \pm 0.41^{\mathrm{a}}$ & $3.2 \pm 0.43^{\mathrm{b}}$ \\
Transferable embryos (grade 3) & $2.0 \pm 0.26$ & $2.5 \pm 0.27$ \\
Degenerate embryos (grades 4 and 5) & $1.9 \pm 0.40$ & $2.9 \pm 0.42$ \\
Unfertilized ova & $0.9 \pm 0.23$ & $0.9 \pm 0.24$ \\
& & \\
\hline
\end{tabular}

PGF $_{2 \alpha}$ : prostaglandin $F_{2 \alpha}$. PRID: progesterone-releasing intravaginal device. ${ }^{\text {ab }}$ Means within a row with different superscripts differ significantly $(P<0.05)$.

into two aliquots, one was frozen immediately $\left(50 \times 10^{6}\right.$ spermatozoa per straw), and the fresh aliquot was diluted $\left(25 \times 10^{6}\right.$ spermatozoa per straw) in Caprogen diluent, stored at $4^{\circ} \mathrm{C}$ and used the same afternoon and the following morning.

\section{Hormone defermination}

Jugular blood samples were collected at the time of the first, third, fifth, sixth, seventh and eighth $\mathrm{pFSH}$ injections. Samples were kept at room temperature for $1 \mathrm{~h}$ and stored at $4^{\circ} \mathrm{C}$ overnight. After centrifugation at $700 \mathrm{~g}$ for $20 \mathrm{~min}$, the serum was decanted and stored at $-20^{\circ} \mathrm{C}$ until assayed for progesterone using the non-extraction assay of Ronayne and Hynes (1990). The inter- and intra-assay coefficients of variation for a pool of samples containing 0.4, 2.2 and $3.5 \mathrm{ng}$ progesterone $\mathrm{ml}^{-1}$ were $11.7,7.8$ and $10.9 \%$ and $2.4,1.0$ and $2.8 \%$, respectively. The sensitivity of the progesterone assay was $0.1 \mathrm{ng} \mathrm{ml}^{-1}$.

\section{Embryo classification}

Heifers were killed seven days after oestrus and the reproductive tracts recovered within $20 \mathrm{~min}$ of death. The numbers of corpora lutea and large follicles ( $\geq 10 \mathrm{~mm}$ ) on each ovary were recorded. Each reproductive tract was severed at the uterotubal junction and the uterine horns flushed separately with $20 \mathrm{ml}$ of phosphate-buffered saline and $3 \%$ heatinactivated steer serum (Goulding et al., 1990). Embryos were recovered, counted, examined and morphologically graded by the same operator on a scale of 1-5 (Boland et al., 1978). Grade 1 and 2 embryos were classified as suitable for freezing, grade 3 embryos were classified as suitable for transfer only, while grade 4 and 5 embryos were of poor quality or degenerate.

\section{Statistical analysis}

The effect of synchronization, semen type and site of semen deposition on variables relating to embryo quality and recovery were analysed using ANOVA methods appropriate to a three factor completely randomized design. Least square means were used for comparison purposes. The model mean square error term was used to estimate SEMs and linear contrasts. The mean progesterone concentrations at the time of pFSH injections were tested for significant differences using a $t$ test. The rates of progesterone decline after cloprostenol administration were compared by regressing the logarithm of progesterone concentrations against time.

\section{Results}

\section{Method of synchronization}

The method of synchronization did not affect the oestrous response, number of ovulations, large follicles, embryos recovered or transferable and degenerated embryos (Table 2). However, the number of freezable embryos was lower in heifers given $\mathrm{pFSH}$ in association with PRID compared with $\mathrm{PGF}_{2 \alpha}$ at mid-cycle (Table 2). The stage of the cycle at the time of PRID insertion affected the superovulatory response obtained; the numbers of ovulations, large follicles and embryos recovered were significantly lower $(P<0.04)$ in heifers given PRIDs during the early luteal phase than at other stages of the oestrous cycle (Table 3). Heifers treated during the early luteal phase had significantly fewer $(P=0.01)$ large follicles than did heifers treated during the mid-luteal phase. There were significantly more $(P=0.03)$ transferable embryos recovered from heifers given a PRID during the late luteal phase compared with during the early phase of the cycle.

\section{Type of semen}

The use of fresh or frozen-thawed semen had no effect on the number of embryos recovered but the use of frozenthawed semen in heifers given a PRID resulted in the recovery of fewer grade 1 and 2 embryos and an increase in the number of grade 4 and 5 embryos, compared with heifers receiving 
Table 3. Superovulatory response (injections of porcine FSH twice a day for 4 days) and embryo production rate (mean \pm SEM) in heifers given $\mathrm{PGF}_{2 \alpha}$ at mid-cycle (days 11-13), or a 7-day PRID treatment and PGF ${ }_{2 \alpha}$ before PRID removal. PRIDs were inserted at the early, mid- or late luteal phase of the oestrous cycle

\begin{tabular}{|c|c|c|c|c|}
\hline \multirow[b]{2}{*}{ Number of } & \multicolumn{4}{|c|}{ Stage of the cycle at PRID insertion } \\
\hline & Early & Mid & Late & $\mathrm{PGF}_{2 \alpha}$ \\
\hline Heifers & 35 & 25 & 24 & 91 \\
\hline Ovulations & $11.8 \pm 1.66^{\mathrm{a}}$ & $18.5 \pm 1.96^{b}$ & $19.1 \pm 2.04^{\mathrm{b}}$ & $13.3 \pm 1.03^{\mathrm{a}}$ \\
\hline Large follicles & $1.7 \pm 0.37^{\mathrm{a}}$ & $3.2 \pm 0.44^{\mathrm{b}}$ & $2.8 \pm 0.45^{\mathrm{ab}}$ & $2.3 \pm 0.23^{\mathrm{ab}}$ \\
\hline Embryos recovered & $6.4 \pm 1.13^{\mathrm{a}}$ & $10.5 \pm 1.46^{b}$ & $11.0 \pm 1.47^{\mathrm{b}}$ & $9.1 \pm 0.70^{b}$ \\
\hline Freezable embryos (grades 1 and 2) & $3.0 \pm 0.66^{\mathbf{a}}$ & $3.3 \pm 0.79^{\mathrm{ab}}$ & $3.5 \pm 0.82^{\mathrm{ab}}$ & $4.4 \pm 0.41^{b}$ \\
\hline Transferable embryos (grade 3 ) & $1.6 \pm 0.40^{a}$ & $2.8 \pm 0.48^{\mathrm{ab}}$ & $3.4 \pm 0.52^{\mathrm{b}}$ & $2.0 \pm 0.23^{\mathrm{a}}$ \\
\hline Degenerate embryos (grades 4 and 5) & $1.6 \pm 0.63$ & $3.4 \pm 0.74$ & $3.4 \pm 0.81$ & $1.9 \pm 0.38$ \\
\hline Unfertilized ova & $0.5 \pm 0.37$ & $1.3 \pm 0.44$ & $1.1 \pm 0.46$ & $0.9 \pm 0.23$ \\
\hline
\end{tabular}

$\mathrm{PGF}_{2 \alpha}$ : prostaglandin $\mathrm{F}_{2 \alpha}$. PRID: progesterone-releasing intravaginal device. ${ }^{\text {ab }}$ Means within a row with different superscripts differ significantly $(P<0.05)$.

Table 4. Superovulatory response (injections of porcine FSH twice a day for 4 days) and embryo production rate (mean \pm SEM) in heifers given PGF $_{2 \alpha}$ at mid-cycle (days I1-13), or on the fourth day of a 7-day PRID treatment. Heifers were inseminated with fresh or frozen-thawed semen (results pooled across different sites and numbers of straws)

\begin{tabular}{|c|c|c|c|c|}
\hline \multirow[b]{4}{*}{ Number of } & \multicolumn{4}{|c|}{ Method of synchronization } \\
\hline & \multicolumn{2}{|c|}{$\mathrm{PGF}_{2 \alpha}$} & \multicolumn{2}{|c|}{ PRID } \\
\hline & \multicolumn{2}{|c|}{ Semen type } & \multicolumn{2}{|c|}{ Semen type } \\
\hline & Fresh & Frozen & Fresh & Frozen \\
\hline Heifers & 47 & 48 & 48 & 42 \\
\hline Heifers in oestrus & 43 & 48 & 44 & 40 \\
\hline Ovulations & $14.0 \pm 1.54$ & $12.8 \pm 1.45$ & $15.8 \pm 1.52$ & $15.9 \pm 1.61$ \\
\hline \multicolumn{5}{|l|}{ Embryos } \\
\hline recovered & $8.9 \pm 1.07$ & $9.3 \pm 1.02$ & $8.6 \pm 1.06$ & $9.7 \pm 1.13$ \\
\hline grades 1 and 2 & $4.3 \pm 0.60^{\mathrm{a}}$ & $4.4 \pm 0.56^{\mathrm{a}}$ & $3.9 \pm 0.59^{\mathrm{ab}}$ & $2.5 \pm 0.62^{b}$ \\
\hline grade 3 & $2.0 \pm 0.38$ & $2.1 \pm 0.36$ & $2.2 \pm 0.37$ & $2.9 \pm 0.40$ \\
\hline grades 4 and 5 & $1.9 \pm 0.58^{\mathrm{a}}$ & $2.0 \pm 0.55^{\mathrm{a}}$ & $2.0 \pm 0.57^{\mathrm{a}}$ & $3.8 \pm 0.61^{b}$ \\
\hline Unfertilized ova & $0.9 \pm 0.33$ & $0.8 \pm 0.32$ & $0.5 \pm 0.33$ & $1.4 \pm 0.35$ \\
\hline
\end{tabular}

$\mathrm{PGF}_{2 \alpha}$ : prostaglandin $\mathrm{F}_{2 \alpha}$. PRID: progesterone-releasing intravaginal device. ${ }^{\text {ab }}$ Means within a row with different superscripts differ significantly $(P<0.05)$.

$\mathrm{PGF}_{2 \alpha}$ and frozen-thawed semen (Table 4). The number of straws of semen used did not affect the number or quality of embryos recovered.

\section{Site of semen deposition}

In general, the only effect of site of semen deposition was on the number of grade 3 embryos recovered. The number of grade 3 embryos recovered following uterine deposition of semen was higher than the number recovered after uterine and cervical semen placement $(3.1 \pm 0.36$ versus $2.0 \pm 0.22$; $P=0.01$ ).

\section{Progesterone concentrations}

Progesterone concentrations in treated heifers are given (Fig. 2). At the time of the first, third and sixth pFSH injections, progesterone concentrations in heifers treated with a PRID or given $\mathrm{PGF}_{2 a}$ in the mid-luteal phase of the cycle were higher than in heifers treated with a PRID during the early luteal phase; mid-luteal phase heifers had higher progesterone concentrations than did late-luteal phase heifers $(P<0.05)$. After $\mathrm{PGF}_{2 \alpha}$ injection, the decline in progesterone concentration of heifers given a PRID in the late luteal phase differed from that of heifers given PRID in the early and mid-luteal phase or given $\mathrm{PGF}_{2 \alpha}$ alone $(P<0.03)$.

\section{Discussion}

The main finding from this experiment was that exogenous progesterone treatment during superovulation may alter the yield of high quality embryos recovered. However, there was no major effect of use of fresh semen, site of insemination or 


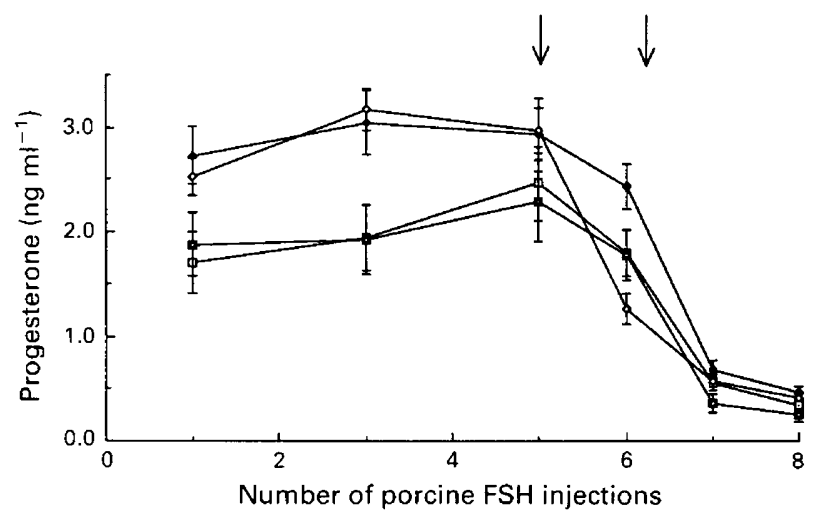

Fig. 2. The mean ( \pm SEM) progesterone concentration at time of porcine FSH injections in superovulated heifers in which luteolysis was induced with prostaglandin $\mathrm{F}_{2 \alpha}(\diamond)$ alone or with a progesteronereleasing intravaginal device inserted at $(\nabla)$ early, $(\bullet)$ mid- or $(\bullet)$ late luteal phase of the oestrous cycle. Arrows indicate prostaglandin $\mathrm{F}_{2 \alpha}$ injections.

number of straws used on embryo yield. The use of progesterone to synchronize oestrus obviates the need to know the specific stage of the oestrous cycle when starting the superovulatory treatment, but this management benefit must be offset against the decrease in the numbers of freezable embryos recovered. There was a clear effect of stage of the cycle at which the PRID was inserted on the number of ovulations and embryos recovered. In practical terms, progesterone treatment should not always be used in donors, but it can be selectively used in heifers from day 6 onwards or in those not detected in oestrus. This will involve one week of oestrous detection and the exclusion of those heifers detected in oestrus from treatment with progesterone.

The lower ovulatory responses to pFSH following PRID insertion in the early luteal phase suggests that the ovary is less responsive to exogenous gonadotrophins than at the mid- and late luteal phase. This result is consistent with other studies in the early luteal phase (Lindsell et al., 1985; Goulding et al., 1990). Initiation of gonadotrophin treatment in the early luteal phase, which in this study was between days 5 and 7 of the cycle, is coincident with the establishment of the first dominant follicle (Savio et al., 1988; Sirois and Fortune, 1988; Knopf et al., 1989). The suppressive effect of the dominant follicle on other recruited follicles in that cohort possibly contributed to a reduced superovulatory response (Grasso et al., 1989; Guilbault et al., 1991). The lowered response cannot be attributed to lower progesterone concentrations, in the early luteal phase, since they were similar to those during the late luteal phase. It is known that progesterone treatment given from the beginning of the cycle will not alter the response to a single injection of pFSH (Vaughan, 1990). However, it is not clear whether pFSH treatment can rescue small atretic follicles leading to the ovulation of aberrant oocytes.

The lowered ovulatory response of heifers given a PRID during the early luteal phase was reflected in the number of embryos recovered. Even though the number of ovulations did not differ significantly between the early luteal phase PRIDtreated heifers and the $\mathrm{PGF}_{2 \alpha}$-treated heifers, significantly fewer embryos were recovered from heifers given PRID in the early luteal phase. This suggests impairment of embryo transport or greater early embryo loss in the PRID-synchronized heifers when treatment was started in the early luteal phase compared with the $\mathrm{PGF}_{2 \alpha}$-heifers. It is therefore clear that superovulation treatments should not be initiated early in the luteal phase, irrespective of method of synchronization used (Goulding et al., 1990).

The numbers of ovulations and of large follicles were not different between the $\mathrm{PGF}_{2 \alpha}$ and PRID treatments when data for all stages of the cycle were combined. This is in agreement with other data reported for use of the PRID, although using a different experimental design (Kunkel, 1979). Other studies have been carried out incorporating the synthetic progestagen, norgestomet, to regulate the cycle in a superovulatory regimen, but the results are equivocal with some authors reporting no effect on the ovulatory response (Holtz et al., 1979; Prather et al., 1984; Hill et al., 1986), whereas others reported a detrimental effect (Almeida, 1987; Garcia-Winder et al., 1988). Information concerning the precise stage of the oestrous cycle at which norgestomet treatment was started might facilitate interpretation of these conflicting results.

In the study reported here the oestradiol capsule was removed from the PRID at insertion and this may have influenced the response. Progesterone concentrations resulting from use of a PRID for 7 days would not affect the turnover of dominant follicles in heifers during the luteal phase, but would delay ovulation by $1-3$ days in heifers treated during the follicular phase. It is known that oestradiol can affect luteal function and could also affect the pattern of turnover of dominant follicles during the oestrous cycle of treated heifers. Administration of oestradiol at the time of norgestomet insertion has no effect on the ovulatory response ( $W u$ et al., 1988; Bo et al., 1990, 1991), but results in fewer transferable embryos (Bo et al., 1990). When oestradiol injection was given at the same time as $\mathrm{pFSH}$ injection, rather than at norgestomet insertion, superovulation was markedly suppressed (Bo et al., 1991). Thus, we suggest that when progesterone or progestagens are used in conjunction with superovulation treatments, $\mathrm{PGF}_{2 \alpha}$ rather than oestradiol should be the luteolytic agent of choice to avoid effects on dominant follicle turnover.

The critical parameter when comparing differences in superovulation protocol is the number of freezable and transferable embryos produced. The significantly lower number of grade 1 and 2 embryos is a major limitation to the widespread use of a PRID as a method of synchronization in the absence of knowledge of the stage of the oestrous cycle at PRID insertion. The results of this experiment suggest a shift from grade 1 and 2 to grade 3 embryos when the PRID rather than PGF $_{2 \alpha}$ was used. This finding agrees with the finding that norgestomet can affect oocyte quality (Maurer et al., 1987); however, in another study (Hill et al., 1986), stage of the cycle did not affect embryo quality and norgestomet appears to offer an alternative that results in successful superovulation in low fertility donors (Ellington et al., 1987). Thus, the stage of the cycle, the presence of a dominant follicle, the dynamics of recruitment and selection of antral follicles and the health of the oocyte in the preovulatory follicle can all affect embryo production rates. 
In superovulated cows, the fertilization rate is often as low as $65 \%$ and about $15 \%$ of superovulated cows have no fertilized ova (Hasler et al., 1983). It is generally recommended that superovulated cows are inseminated twice with one straw at each insemination (West et al., 1984). Some studies (Donaldson and Ward, 1985; Schiewe et al., 1987) suggest that repeated inseminations are necessary to obtain optimal fertilization rates for the production of transferable embryos. In the study reported here, there was no difference in the number, or quality, of embryos recovered following the use of two or three straws at insemination, suggesting that the third straw of semen did not improve embryo quality. This is in agreement with data of Critser et al. (1980) who examined timing and number of inseminations used. The timing of ovulation in superovulated cows is variable (Yadav et al., 1986) and repeated inseminations at intervals of $12 \mathrm{~h}$ are used in embryo transfer programmes. A high proportion of semen is lost from the reproductive tract within hours of insemination and this suggests that the site of semen deposition influences the distribution of spermatozoa and in turn influences the fertilization rate. In this study, there was a significant effect of site of semen deposition on the number of transferable embryos; uterine insemination yielded a higher number than when combined with cervical deposition. This finding does not support the hypothesis that the depletion of oviductal sperm reservoirs due to the protracted time of ovulation could be overcome by combining the routine intrauterine insemination with simultaneous semen deposition in the cervix (Hunter, 1988). In the present study, thawed, frozen semen combined with PRID synchronization yielded the lowest number of freezable embryos and the highest number of degenerate embryos. This suggests an interaction with frozen semen and PRID synchronization that is not present with fresh semen.

In conclusion our data suggest that a PRID can be used successfully in a superovulatory regimen in cattle with due regard to the stage of the oestrous cycle at insertion. It is suggested that the dominant follicle has a major role in determining the superovulatory response. In addition, high quality thawed, frozen, or fresh semen must be used to ensure a high yield of good quality embryos suitable for freezing or fresh transfer. Two straws of semen are sufficient for insemination of superovulated heifers and there is no advantage in depositing an additional straw in the cervix.

\section{References}

Almeida AP (1987) Superovulation in cattle: a combined treatment using Synchro-Mate-B with either pregnant mare serum gonadotrophin or follicle stimulating hormone (FSH) Theriogenology 27 329-336

Bo GA, Garcia A, Schumann F, Pierson RA and Mapletoft RJ (1990) The effect of Synchro-Mate-B ear implant and estradiol treatment on superovulatory response in the cow Theriogenology 33198 Abstract

Bo GA, Pierson RA and Mapletoft RJ (1991) The effect of estradiol valerate on follicular dynamics and superovulatory response in cows with Synchromate-B implants Theriogenology 36 169-183

Boland MP, Crosby TF and Gordon I (1978) Morphological normality of cattle embryos following superovulation using PMSG Theriogenology 10 175-180

Boland MP, Crosby TF and Gordon I (1983) Ovarian response in ewes following horse anterior pituitary extract and progestagen treatment Animal Reproduction Science 6 119-127

Boland MP, Goulding D and Roche JF (1991) Alternative gonadotrophins for superovulation in cattle Theriogenology 35 5-17
Critser JK, Rowe RF, Del Campo MR and Ginther OJ (1980) Embryo transfer in cattle: factors affecting superovulatory response, number of transferable embryos, and length of post-treatment estrous cycle Theriogenology 13 397-406

Donaldson LE and Ward DN (1985) Superovulation in cattle: dose response to FSH.W with and without LH contamination Theriogenology 23189 Abstract

Ellington JE, Elefson EE and McCall RM (1987) Use of a norgestomet implant as an aid when superovulating low-fertility dairy cattle Theriogenology 27227 Abstract

Garcia-Winder M, Lewis PE, Bryner RW, Baker RD, Inskeep EK and Butcher RL (1988) Effect of age and norgestomet on endocrine parameters and production of embryos in superovulated beef cows Journal of Animal Science 66 1974-1981

Goulding D, Williams DH, Duffy P, Boland MP and Roche JF (1990) Superovulation in heifers given FSH initiated either at Day 2 or Day 10 of the estrous cycle Theriogenology 34 767-778

Grasso F, Guilbault LA, Roy GL, Matton P and Lussier JG (1989) The influence of the presence of a dominant follicle at the time of initiation of a superovulatory treatment on superovulatory responses in cattle Theriogenology 31199 Abstract

Guilbault LA, Grasso F, Lussier JG, Rouillier P and Matton P (1991) Decreased superovulatory responses in heifers superovulated in the presence of a dominant follicle Journal of Reproduction and Fertility 91 81-91

Hasler JF, McCauley AD, Schermerhorn EC and Foote RH (1983) Superovulatory responses in Holstein cows Theriogenology 19 83-99

Hill KG, Bondioli KR and Looney CR (1986) Use of a norgestomet implant in conjunction with follicle-stimulating hormone (FSH) for superovulation of donor cattle Theriogenology 25160 Abstract

Holtz W, Herrmann HH and Voss HJ (1979) Estrus synchronization and superovulation with a subcutaneous gestagen implant (Norgestomet, Intervet) in suckler cows and beef heifers Theriogenology 12 197-206

Hunter RHF (1988) Low incidence of fertilization in superovulated cows: a physiological explanation Veterinary Record 123443

Ireland JJ and Roche JF (1987) Hypothesis regarding development of dominant follicles during a bovine estrous cycle. In Follicular Growth and Ovulation Rate in Farm Animals, pp 1-18 Eds JF Roche and D O'Callaghan. Martinus Nijhoff, Lancaster

Knopf L, Kastelic JP, Schallenberger E and Ginther OJ (1989) Ovarian follicular dynamics in heifers: test of two wave hypothesis by ultrasonically monitoring individual follicles Domestic Animal Endocrinology 6 111-119

Kunkel RN (1979) The use of progesterone-releasing intravaginal devices in the superovulation of donor cows Theriogenology 11102 Abstract

Lindsell CE, Pawlyshyn V, Bielanski A and Mapletoft RJ (1985) Superovulation of heifers with FSH-P beginning on four different days of the cycle Theriogenology 23203 Abstract

Maurer RR, Suss U and Wise TH (1987) Oocyte quality in superovulated beef heifers with and without norgestomet implants Theriogenology 27256 Abstract

Prather RS, Spire MF and Schalles RR (1984) Norgestomet incorporation into a superovulation regime Theriogenology 21256 Abstract

Ronayne E and Hynes N (1990) Measurement of plasma progesterone by extraction and nonextraction radioimmunoassay Irish Journal of Agricultural Research 29 109-115

Savio JD, Keenan L, Boland MP and Roche JF (1988) Pattern of growth of dominant follicles during the oestrous cycle of heifers Journal of Reproduction and Fertility 83 663-671

Schiewe MC, Looney CR, Johnson CA, Hill KG and Godke RA (1987) Transferable embryo recovery rates following different insemination schedules in superovulated beef cattle Theriogenology 28 395-406

Sirois $\mathrm{J}$ and Fortune JE (1988) Ovarian follicular dynamics during the estrous cycle in heifers monitored by real-time ultrasonography Biology of Reproduction 39 308-317

Vaughan L (1990) The Effect of Copper Status and FSH on Follicular Development and Fertility in Heifers PhD Dissertation, National University of Ireland

West G, West C, Risley D and Donaldson L (1984) Effect of breeding regime on percent ova fertilized in superovulated cows Theriogenology 21273 Abstract

Wu M, Wang $\mathrm{H}, \mathrm{Ku} \mathrm{K}$ and Mapletoft RJ (1988) The effect of estradiol with Synchro-Mate-B in the superovulation of beef heifers with FSH-p Theriogenology 29333 Abstract

Yadav MC, Walton JS and Leslie KE (1986) Timing of the onset and duration of ovulation in superovulated beef heifers Theriogenology 26 509-521 